\title{
DESAIN AIRFOIL MENGGUNAKAN SOFTWARE CAEDIUM
}

\author{
Wiji Mangestiyono \\ Program Studi Diploma III Teknik mesin \\ Fakultas Teknik Universitas Diponegoro
}

\begin{abstract}
Wiji Mangestiyono, in paper airfoil design use caedium software explain that caedium and its add-ons combine to form an easy-to-use Computational Fluid Dynamics (CFD) software system that can help to assess the performance of 3D model. Using Caedium add-ons can create any 2D or 3D geometry or import geometry from another CAD package. Then simulate how a gas (e.g. air) or liquid (e.g. water) will flow over and through geometry. Caedium is simple to learn and efficient to use. Every body can study how the physics of its model changes over time or as modify the model in real time. Caedium's unified simulation environment makes it easy to change the model on the fly and quickly see the results of the changes.
\end{abstract}

Keywords : Caedium, Airfoil, Computation Fluid Dynamics

\section{LATAR BELAKANG}

Airfoil secara sederhana bisa dikatakan sebagai penampang dari blade (sudu turbin) pada berbagai irisan. Perbandingan antara lift dengan drag adalah kriteria kunci dalam membandingkan kualitas dari sebuah airfoil. Dari beberapa penelitian menunjukkan bahwa bila nilai L/D meningkat maka coefficient of power akan meningkat pula secara berurutan. Pada pengoperasian yang berkelanjutan nilai L/D hanya memiliki deviasi yang kecil yaitu terjadi pada kondisi bila gaya lift terlalu besar. Untuk alasan struktur disain ketebalan airfoil sangat diperlukan dikarenakan untuk pemasangan struktur penguat didalam blade.

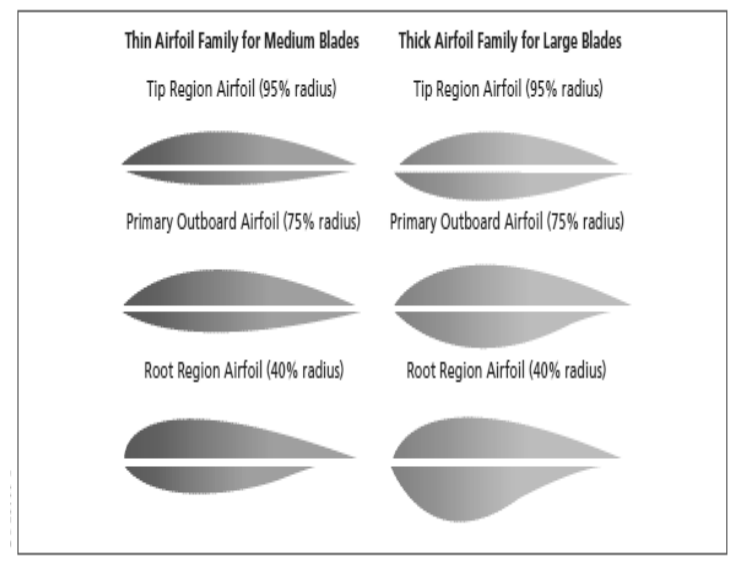

Gambar 1. Airfoil untuk medium blade dan large blade (Office of Geothermal and Wind Energy Program, 2000)

Dalam gambar 1. terlihat bahwa airfoil untuk medium blade terlihat lebih ramping dengan bagian atas mempunyai dimensi lebih tipis sedang bagian bawah cenderung lebih lebar dengan maksud untuk meningkatkan kekuatan struktur.

Performa maksimal suatu rotor membutuhkan konfigurasi sudu meliputi variasi radial dari chord dan twist angle, dimana tergantung pada hasil lokal dari lift coefficient dan flow angle. Desain blade haruslah dikompromikan terhadap aspek-aspek meliputi airfoil, kekuatan struktur, pembatasan getaran dan pertimbangan nilai ekonomis. Performa maksimal suatu rotor blade menghendaki sisi chord dengan bentuk hiperbol. Biasanya hal ini dihindari dengan tujuan untuk mempermudah dalam menyusun disain serta dalam pembuatannya sehingga menjadi berbentuk trapezoidal. Perubahan yang dilakukan menyebabkan penurunan coefficient of power akan tetapi tidak begitu besar seolah-olah merupakan deviasi dari nilai maksimum yang didapatkan dari performa rotor blade.

Distribusi tebal blade secara kuat sangat dipengaruhi oleh kebutuhan kekuatan struktur untuk mengantisipasi gaya-gaya yang bekerja pada blade yaitu momen bengkok akibat dari drag maupun lift force, gaya centrifugal akibat putaran. Pada umumnya blade thickness meningkat pada bagian mendekati pangkal dan mengecil pada bagian mendekati ujung. Untuk bagian pangkal blade banyak faktor yang harus diselaraskan sebagai contoh ukuran flens pengikat blade pada hub, kekuatan struktur untuk menahan gaya akibat momen bengkok.

Distribusi blade twist adalah perubahan sudut kemiringan airfoil mulai dari ujung blade hingga pada bagian pangkal. Perubahan ini dilakukan untuk mendapatkan nilai maksimum dari kerja rotor. Pada umumnya twist angle pada bagian ujung mempunyai nilai kecil dan selanjutnya akan semakin besar bila mendekati pangkal.

Dari beberapa uraian di atas maka dapat terungkap beberapa permasalahan dalam mendesain airfoil yaitu :

- Dengan adanya pemilihan jenis airfoil yang berbeda pada tip region, primary outboard dan root region, bagaimanakah bentuk airfoil pada pergantian jenis airfoil yang dipilih? 
- Dengan adanya perubahan jenis airfoil pada sebuah sudu menyebabkan aliran udara di sekitar airfoil berubah. Bagaimanakah bentuk perubahan yang terjadi, menguntungkan atau bahkan merugikan?

Untuk menjawab permasalahan tersebut maka penulis mencoba untuk memberikan solusi dengan memanfaatkan software Caedium.

\section{COMPUTATIONAL FLUID DYNAMICS}

Penggunaan alat bantu Caedium dapat mempermudah dalam menyusun desain 2D dan geometri 3D atau mengimpor dari geometri dari paket lain yaitu CAD selanjutnya mensimulasikan bagaimana aliran udara atau air melewati geometri yang dibentuk. Pengoperasian sistem bisa dilakukan dengan basis program yang disukai yaitu Windows, Mac OS X, atau Linux.

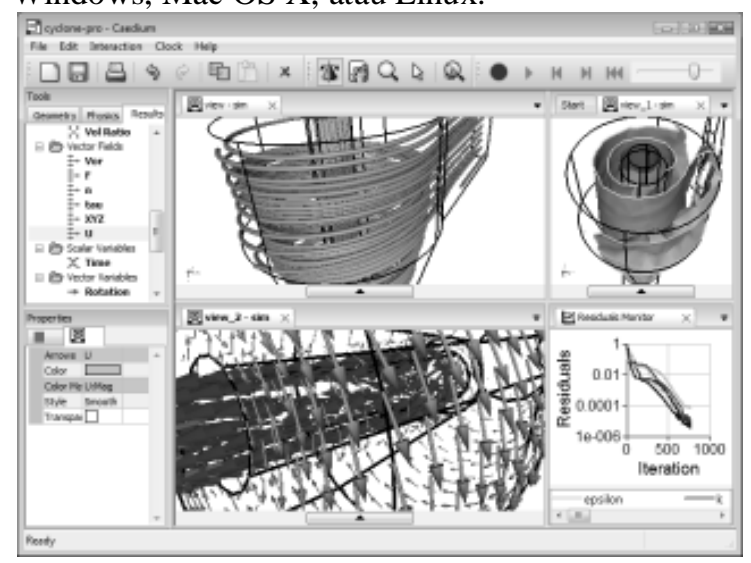

Gambar 2. Simulasi aliran udara pada airfoil

Untuk membuat kreasi desain dengan menggunakan Caedium dengan dilengkapi simulasi aliran udara maka beberapa program pendukung harus dipersiapkan, diantaranya :

- Professional: didapatkan pada seluruh alat bantu Caedium sebagai paket bonus.

- RANS Flow: adalah program RANS CFD yang digunakan untuk mensimulasikan kerapatan gas atau aliran liquid dengan pemindahan panas pada ruang disekitarnya untuk menentukan arah aliran dan gaya yang terjadi ( lift atau drag).

- Panel Flow: untuk mensimulasi aliran gas atau fluida di sekitar airfoil untuk menentukan arah aliran dan gaya yang bekerja pada airfoil.

- Builder: untuk membuat dan memodifikasi desain 2D atau 3D.

- Transient : untuk menentukan waktu dimana tergantung pada hasil simulasi dan visualisasi.

- Exchange: untuk mengimpor dan mengekspor IGES, STEP dalam format filenya

- Viz Export: mengekspor hasil 3D dengan resolusi tinggi, kualitas bagus pada paket visualisasi lain.
Caedium sangat mudah untuk dipelajari dan efisien dalam penggunaan desain airfoil. Bila fisik dari desain airfoil berubah maka pengaruhnya dapat terlihat secara langsung sehingga mempermudah desainer dalam menentukan langkah akhir dalam memilih keanekaragaman desain.

Beberapa contoh model yang bisa dianalisis menggunakan Caedium adalah :

- Aliran udara pada sayap pesawat terbang.

- Aliran air pada sekeliling kapal selam.

- Aliran udara di atas bodi mobil yang bergerak.

- Aliran air di dalam pipa.

\section{EVALUASI DAN PERBANDINGAN KONSEP}

Mengevaluasi hasil Caedium bisa dilakukan dengan berbagai cara, yaitu :

- Membandingkan hasil simulasi desain airfoil produk Caedium dengan hasil kamera melalui pengambilan gambar dari berbagai sudut pandang. Dengan cara membandingkan seperti ini maka keandalan Caedium akan bisa dibuktikan secara jelas dimana detilnya mampu menunjukkan bukti kualitas gambar yang dihasilkan.

- Membuat plot 3D dari airfoil yang didesain dan menganalisis hasil yang didapat. Kesempurnaan hasil menunjukkan kualitas penggunaan Caedium dalam membuat desain airfoil.

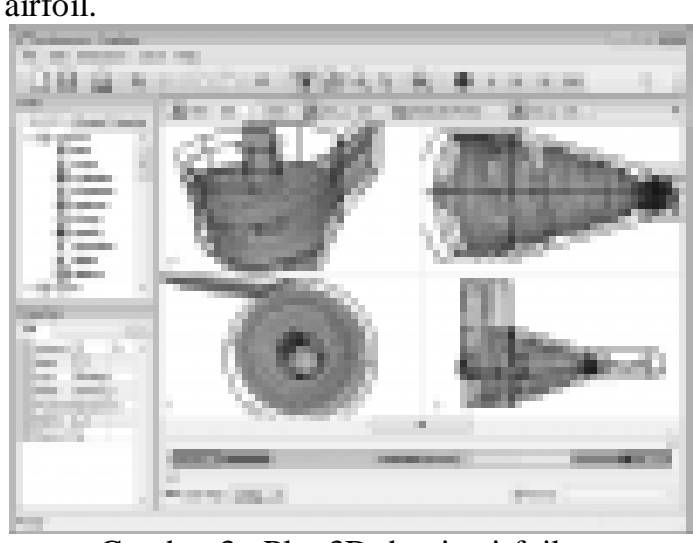

Gambar 3. Plot 3D desain airfoil

- Membuat plot 2D dan membandingkan dengan data yang diimpor dengan hasil simulasi. Hasil perbandingan ini mampu memberikan keyakinan bahwa Caedium mempunyai kualitas yang baik dalam membuat desain.

\section{HASIL DESAIN}

Untuk mempelajari desain airfoil yang dihasilkan perlu dilaksanakan beberapa langkah seperti berikut ini :

- Cetak desain yang dihasilkan. Hasil cetakan desain merupakan bukti nyata dari desain airfoil yang telah dikerjakan dan mempunyai ukuran baku atau dalam arti sudah tidak mungkin berubah-ubah lagi bila sudah dicetak. 
- Simpan desain airfoil dalam format standar (png, jpg, bmp, xpm, pnm, tif)

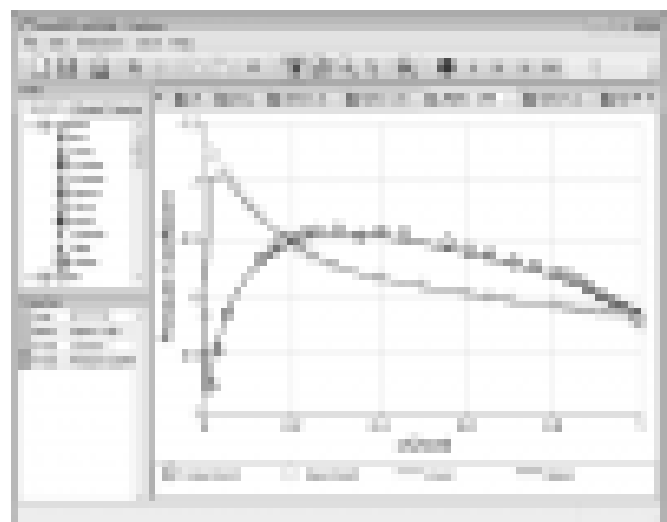

Gambar 4. Plot 2D dengan perbandingan data impor

- Impor/eksport plot data sebagai Comma Separated Values (CSV)

- Simpan desain dalam format file native sym sehingga bisa dikaji secara interaktif dalam Caedium.

- Impor gambar latar belakang sehingga meningkatkan nilai artistik desain.

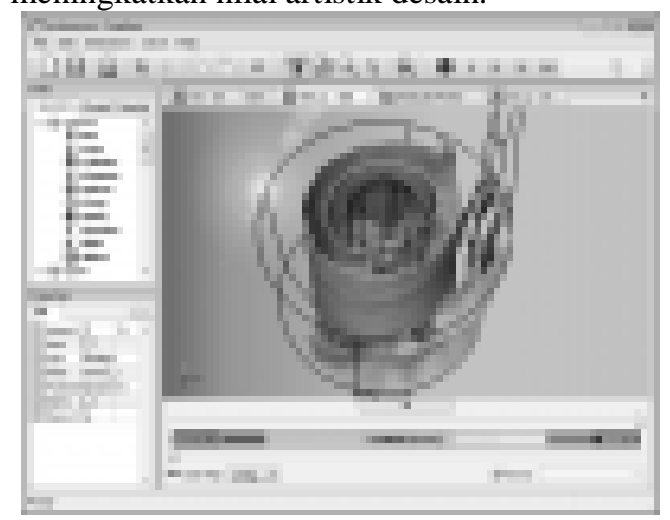

Gambar 5. Penambahan background

- Tambahkan gambar pada permukaan geometri sebagai contoh logo dari produk yang dibuat.

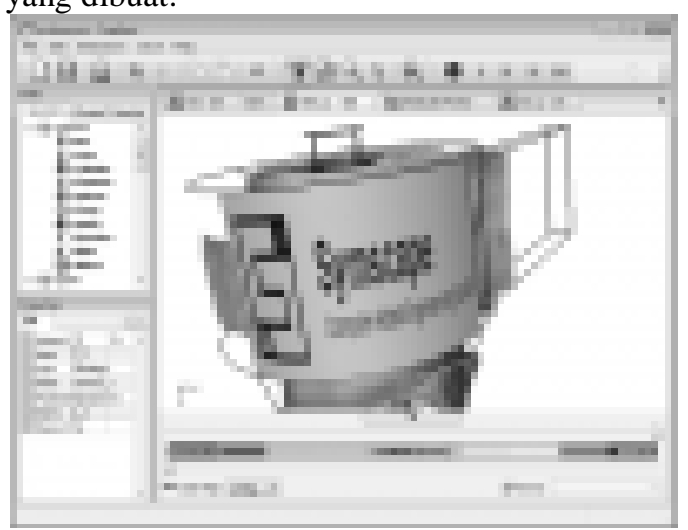

Gambar 6. Penambahan logo pada permukaan geometri

\section{KEUNGGULAN PENGGUNAAN CAEDIUM}

- Menghasilkan desain airfoil dalam waktu yang jauh lebih singkat.

- Memiliki sensitivitas Drag'n'Drop tools.

- Memiliki pilihan yang interaktif dalam hal geometri melalui window.

- Disertai suara untuk mengiringi gerakan selama pelaksanaan simulasi, misal suara air mengalir, suara angin, suara gesekan dan sebagainya.ebuah desain.

- Memberikan hasil nilai properti yang nyata sebagai sebuah desain airfoil.

- Memiliki filter untuk mempermudah pemilihan geometri airfoil.

- Mengutamakan terminologi teknik pemecahan masalah.

- Pipeline Driven Technology untuk penyederhanaan otomasi simulasi upstream sebagai prasyarat meshing.

- Intuitif geometri, berdasar pada akurasi kontrol dimana dapat berpengaruh terhadap ketidak terhubungan simulasi geometri.

\section{KESIMPULAN}

- Penggunaan software Caedium dalam membuat desain airfoil dapat menghemat waktu sehingga menurunkan cost atau biaya produksi.

- Caedium dapat menghasilkan gambar dengan resolusi tinggi hingga kualitas gambar bisa diandalkan.

- Penambahan suara dalam mengiringi aliran air, udara menambah kualitas pada saat pelaksanaan displai.

- Dapat membantu penyambungan airfoil pada tip region, primary outboard dan root region sehingga dapat meningkatkan coeeficient of power dari airfoil.

\section{DAFTAR PUSTAKA}

1. Bertagnolio, Frank, Sorensen, Niel, Johansen,J eppe, Fuglsang, Peter, 2001, Wind Turbine Airfoil Catalogue, Riso National Laboratory, Denmark.

2. Cho, Taehwan, Kim, Cheolwan, 2012, Wind tunnel test results for a 2/4,5 scale MEXICO rotor, Renewable Energy, 42 : 152 - 156.

3. Guerri, Ouhiba, Hamdouni, Azis, Sakout, Anas, 2009, Fluids structure interaction of wind turbine airfoil, Wind Engineering, 32 : 539 557.

4. Office of Geothermal and Wind Technology, Advanced Airvoil of Wind Turbines, http:/www.eren.do.gov/win, August 8, 2000.

5. Symscape Computational Fluid Dynamics, NACA Airfoil Computation, http://www.symscape.com, October 16, 2007. 